\title{
FOOTBALL AND MONDIALISATION
}

\section{Futebol e mundialização}

\author{
Luiz Carlos Ribeiro*
}

BONIFACE, Pascal. Football \& mondialisation. Paris: Armand Colin, 2006.

Diretor do Institut de Relations Internationales et Estratégiques (IRIS), professor do Institut d'Études Européenes de l'Université Paris VIII e membro do Comitê Consultivo sobre o desarmamento junto ao Secretário Geral da ONU, Pascal Boniface possui uma extensa produção bibliográfica sobre a Europa e suas relações internacionais.

Do mesmo modo, é um fanático torcedor de futebol, tendo escrito livros e artigos sobre o tema, quase sempre nessa ótica das relações internacionais dos clubes e dos selecionados europeus. É nessa expectativa que me interessei pelo livro Football \& mondialisation, lançado na França em meados de 2006.

No Brasil a pesquisa acadêmica sobre o tema ainda dá seus primeiros passos, existindo sobre os esportes em geral, e o futebol em particular, um forte preconceito por parte dos pesquisadores ligados à universidade $\mathrm{e}$ à pós-graduação, em especial na área da História.

O que chama a atenção, nesse aspecto, é que essa indisposição ao mesmo tempo em que é comum nos países onde o futebol se apresenta como um fenômeno das massas, guarda nuances significativas.

O fator predominante que identifica a indisposição é que, ao considerar o futebol uma manifestação cultural de massa, o determina como um lugar privilegiado da alienação, da incapacidade da consciência social dessas massas. Essa posição é recorrente, por exemplo, nas pesquisas das ciências humanas de França e Brasil.

* Doutor em História Social. Professor do Departamento de História da UFPR. 
A diferença - e é isso que nos estimula a apresentação dessa obra de Boniface - é que no Brasil os pesquisadores pouco se dispõem a enfrentar a questão. Simplesmente tomam o esporte como um tema social e politicamente menor. Na melhor das hipóteses é tratado como exótico ou de importância periférica. O futebol, enquanto manifestação das massas, é visto como incapaz de uma alguma explicação racional sobre o mundo social e político, a que ele obviamente pertence.

De modo diverso ocorre em alguns países da Europa, em especial na França. Apesar de analisado na maioria das vezes também como uma oposição simplista de engajamento ou alienação - ou lugar e não-lugar da política - não predomina o silêncio, mas uma intensa discussão. São partidários dessa síntese do futebol como alienação e "ópio do povo", por exemplo, Jean-Marie Brohm e Marc Perelman (2006). Sobre essa e outras questões polêmicas que envolvem o futebol, Boniface se posiciona com clareza.

Estruturado com uma introdução, seis capítulos e uma conclusão, Football \& mondialisation aborda com um olhar marcadamente francês as questões mais importantes que envolvem o futebol contemporâneo em todos os cantos do mundo onde é uma paixão generalizada.

Ao esboçar na introdução o conteúdo geral da obra, Boniface deixa claro sua paixão pelo futebol e, conseqüentemente, a premência de analisálo não apenas pela ótica da racionalidade científica, mas também pela afetividade, ou seja, pela passionalidade que lhe é intrínseca. Apesar de não desenvolver uma teoria sobre essa forma de análise, o seu envolvimento afetivo com o futebol permite-lhe a sensibilidade de procurar compreender e preservar as tensões entre razão e paixão no estudo das relações do futebol com a sociedade.

Desse modo, Boniface aproxima-se da tradição eliaseana de estudos dos esportes (e da sociedade em geral), quando se dispõe a descrever e analisar os principais elementos configuracionais do futebol e de suas relações de equilíbrio e desequilíbrio (ELIAS, 1990, 1992, 1994).

Com uma narrativa agradável, o texto de Boniface nos faz lembrar também alguns de nossos cronistas esportivos, como Armando Nogueira, Tostão e Juca Kfouri.

Logo, o eixo da obra é o futebol e as atuais relações internacionais de globalização, que desorganiza e reorganiza o mapa geopolítico, em especial na Europa. 
Já no primeiro capítulo - Le football: Stade supreme de la mondialisation - manifesta-se a segura formação do autor nas relações internacionais francesas e européias. Entre outros recortes, por exemplo, destaca o fato de a FIFA - Fédération Internationale de Football Association (fundada em 1904), entidade que congrega e organiza o futebol em todo o mundo, compreender um número maior de países que a própria ONU. São 207 estados-membros da FIFA, contra 191 da ONU. O que o autor evidencia não é apenas a abrangência numérica, mas a importância política da penetração logo, reconhecimento diplomático - do futebol em regiões que a ONU não teve êxito no seu reconhecimento e na obtenção de consenso político. Alguns exemplos citados são bastante elucidativos: a Escócia, associada à FIFA desde 1910, mas politicamente reconhecida apenas como parte do Reino Unido britânico; a Palestina, filiada à FIFA desde 1998, mas um tormento para as resoluções políticas da ONU. Boniface sintetiza essa relação da seguinte forma: "Quando se trabalha com temas tão deprimentes, como o Oriente Próximo, o terrorismo ou a política exterior americana, a geopolítica do futebol é um espaço de alívio e distensão, uma verdadeira fonte da juventude." (p.12)

Como é explicitamente sua intenção, a discussão transborda para um dos temas centrais na Europa hoje: a consolidação da União Européia:

Temos de modo recorrente medo que a Europa apague as identidades nacionais. No domínio do futebol, não há nenhum risco. Isto porque as equipes nacionais permanecem como fortes demarcadores e reafirmadores identitários. (p. 37)

No segundo capítulo - Les champions de l'idée nationale Boniface destaca a complexidade do jogo, fazendo um paralelo com os conflitos políticos (e bélicos) internacionais. Diferentemente das relações políticas internacionais, no jogo de futebol a oposição não supõe a supressão do oponente. Não apenas a manutenção do oponente é inerente - pois sem ele o jogo deixaria de existir -, como é fator de afirmação identitária do grupo, local ou nacional.

A definição clássica de Estado repousa sobre três critérios tradicionais: um território, uma população, um governante. Nós podemos adicionar um quarto: uma equipe nacional de futebol! Nos tempos atuais, a indepen- 
dência nacional se caracteriza pela capacidade de defender a fronteira, fabricar a moeda e disputar as competições internacionais de futebol.

$\mathrm{O}$ autor acredita ser mais fácil à população de um Estado jovem mobilizar-se pelo selecionado nacional de futebol, do que com a criação de uma embaixada na ONU. (p. 52) E, nessa direção, analisa a relevância que 0 futebol teve (e tem) na formação de diversas nacionalidades, em especial com a crise no Leste europeu no final dos anos oitenta.

No terceiro capítulo - Le Mondial plutôt que la guerre mondial -, com uma forte dose de otimismo mas de modo algum ingenuidade, Pascal Boniface afirma a capacidade que o futebol tem em reforçar a amizade e a harmonia entre os povos. Com isso se abre para uma discussão que (re)aparece na vida intelectual e política francesa, a de considerar o futebol sinônimo de alienação e de "ópio do povo". Logo, algo a ser negado ou silenciado, como fez durante mais de um século certa tradição marxista com relação ao que não considerava manifestação de plena consciência social.

Assim, pergunta-se o autor no quarto capítulo: o futebol será um nouvel opium du peuple? Constatação que rebate com veemência, sem contudo abordar o caráter abstrato e exterior que essa conceituação contém, na medida em que se constitui numa afirmação que responde mais à lógica interna da teoria que a formula, do que à prática social efetiva dos indivíduos.

É evidente, afirma Boniface, que o futebol serve a interesses ideológicos na legitimação de interesses autoritários, de regimes políticos e do mercado de consumo. Mas é sobretudo um lugar efetivo da política, no seu sentido amplo e complexo, sobre o qual esse tipo de crítica prefere silenciarse.

Não foi o futebol que eregiu a supremacia fascista na Copa do Mundo na Itália em 1934, como não foi o futebol que glorificou a ditadura militar na Copa do Mundo na Argentina em 1978, afirma Boniface.

De outro lado, os espetáculos esportivos não só expuseram ao mundo esses regimes, como possibilitaram que manifestações contrárias pudessem ganhar destaque na mídia internacional. Nos estádios de futebol registraram-se manifestações de apoio e de repúdio a sistemas políticos, seja os autoritários, seja aqueles que lutaram por independência nacional ou por afirmação democrática. Assim, afirma o autor, reduzir o futebol à idéia 
de "ópio do povo" é simplista e revela um desconhecimento do cotidiano esportivo, além de um profundo preconceito social e cultural.

No seu quinto capítulo - Qui gouverne le foot? - Boniface descreve com detalhes as relações tensas entre a UEFA - Union of European Football Associations, basicamente sob a direção do G14 - que congrega os clubes mais ricos do futebol europeu e mundial - e a FIFA. Enquanto esta tem um papel político de congregação internacional, o que significa atender as demandas esportivas (e políticas) as mais diversas no mundo todo, a UEFA, liderada pelo G14, é "um grupo de interesse econômico" em defesa exclusiva das necessidades financeiras dos clubes europeus e pouco preocupados com relações diplomáticas amplas. Como seus interesses são clubísticos, a relação com as seleções nacionais que têm jogadores atuando na Europa é sempre conflituosa. As estrelas do futebol deixam de atuar na Europa para jogar por seus selecionados nacionais, podem se machucar e trazer prejuízos vultosos aos clubes. Aqui, como em todo o texto, se manifesta a posição do autor com relação à consolidação política da união européia. Sua ótica - assumidamente francesa - não ignora o peso dos interesses econômicos na estrutura do futebol, mas torce pela harmonia das relações diplomáticas, seja em termos da União Européia, seja mundialmente. A provável eleição de Franz Beckenbauer (ex-jogador e atual dirigente de futebol alemão) contra Michel Platini (ex-jogador e atual dirigente de futebol francês) para a direção da UEFA em 2007 permite a conclusão de Boniface: "O alemão aparece, em todo caso, menos ligado à ética e aos valores que o francês, e por isso deverá obter apoio do G14". (p. 150) ${ }^{1}$

No sexto e último capítulo - Footbal et racismo: le mouchoir et les larmes - Boniface adota a mesma postura de criticar a ingenuidade de se atribuir ao futebol a causa ou o desenvolvimento do racismo. Assim como não será acabando com o futebol (suposto ópio do povo) que se esgotarão os regimes autoritários, também não será suficiente para acabar com as manifestações ultradireitistas e racistas. Se for verdadeiro que os estádios (e seus arredores) têm sido locais de violência e de racismo, também têm sido de harmonia e paz entre os povos. Cita entre outros casos, o seleciona-

1 Nesse aspecto o autor errou na suas previsões. Articulações políticas fizeram com que Beckenbauer sequer lançasse sua candidatura à direção da UEFA, permitindo a vitória do francês Platini sobre o então presidente Lennart Johansson. Uma vitória apertada de 27 votos contra 23 e duas abstenções. 
do francês "black, blanc, beur" como exemplo da tensa contradição racial e política. E conclui:

Escola de amizade e de fraternidade, o futebol é o melhor meio de lutar contra o racismo. (p. 151)

Se existem a violência e os excessos nos estádios, excessos que não podemos negar e que é preciso condenar e combater, eles não devem ser a árvore que esconde a floresta. O futebol é, ao contrário, um formidável vetor de fraternidade e de camaradagem. (p. 169)

\section{Referências}

BROHM, Jean-Marie; PERELMAN, Marc. Le football, une peste émotionnelle. Paris: Gallimard, 2006.

ELIAS, Norbert. Esboço de uma teoria civilizacional. In: O processo civilizacional. 2 v. Lisboa: Publicações Dom Quixote, 1990.

ELIAS, Norbert. A sociedade dos indivíduos. Rio de Janeiro: Jorge Zahar Editor, 1994.

ELIAS, Norbert; DUNNING. Eric. A busca da excitação. Lisboa: Difel, 1992.

2 beur - palavra de origem árabe (inversão de arabeu - beur) tornou-se expressão de gíria de conotação pejorativa para designar a cultura dos jovens descendentes de emigrados (muçulmanos ou não) da África do Norte instalados na França. 